\section{“O QUE PODE UM CORPO?”: DEVIR ATLETA E A POTENNCIA DOS FENÔMENOS}

\author{
“WHAT CAN A BODY DO?”: ATHLETES' BECOMING AND THE POTENTIAL OF \\ PHENOMENA
}

“QQUÉ PUEDE UN CUERPO?”: DEVENIR ATLETA Y LA POTENCIA DE LOS FENÓMENOS

\author{
Elder Silva Correia*, Fabio Zoboli**, Renato Izidoro da Silva**
}

Keywords:

Body. Athletes.

Sports.

Philosophy.

Resumo: No contexto esportivo os corpos dos atletas comumente aparecem associados a elementos de outras ordens: animais, máquina, fenômenos sobrenaturais, dentre outros. O objetivo deste ensaio é fazer uma leitura dessas analogias a partir da compreensão de Deleuze e Guattari acerca da filosofia dos afetos de Spinoza, mais precisamente utilizandonos dos conceitos de potência, devir e afectos. A partir desses conceitos consideramos que o fato de criarmos heterônimos para atletas expressa três pontos acerca da relação compósita do corpo com o esporte: i) essa comparação entre atletas e fenômenos de outras ordens não são simples associações ou metáforas, mas devires; ii) esses devires expressam e tornam perceptíveis novas potências, ou potências estranhas dos corpos na relação com o esporte; iii) o território esportivo paradoxalmente além de ser um dispositivo disciplinar e de tecnificação do corpo, é também um território que possibilita a ampliação da potência dos corpos como descobertas de devires.

Abstract: In the sporting context, athletes' bodies are usually associated with other types of elements: animals, machine, supernatural phenomena, among others. This essay reads those analogies under Deleuze and Guattari's understanding of Spinoza's philosophy of affection, more precisely using concepts of power, becoming, and affectos. Under these concepts we consider that creating heteronyms for athletes expresses three points about bodies' composite relation to sport: i) this comparison between athletes and other phenomena are not simple associations or metaphors; they are becomings; ii) these becomings express new potentials and render them perceptible as well as bodies' strange potentials regarding sport; iii) paradoxically, besides being a disciplinary and body technification device, sports territory also allows amplifying bodies' becoming as discoveries of becoming.

Palabras clave: Cuerpo.

Atleta.

Deportes.

Filosofía.
Resumen: En el contexto deportivo los cuerpos de los atletas aparecen asociados a elementos de otros órdenes: animales, máquina, fenómenos sobrenaturales, entre otros. El propósito de este ensayo es hacer una lectura de estas analogías a partir de la comprensión de Deleuze y Guattari sobre la filosofía de los afectos de Spinoza, más precisamente utilizando los conceptos de potencia, devenir y afectos. A partir de esos conceptos consideramos que el hecho de crear heterónimos para atletas expresa tres puntos acerca de la relación del cuerpo con el deporte: i) la comparación entre atletas y fenómenos de otras órdenes, no constituyen solo asociaciones o metáforas, sino devenires; ii) estos devenires expresan y hacen perceptibles nuevas potencias, o potencias extrañas de los cuerpos en la relación con el deporte; iii) el territorio deportivo, además de ser un dispositivo disciplinario y de tecnificación del cuerpo, es también es un territorio que permite el aumento de la potencia de los cuerpos como descubrimientos de devenires.
*Universidade Federal do Espírito Santo. Vitória, ES, Brasil. E-mail: eldercorreia21@gmail.com

**Universidade Federal de Sergipe. Aracaju, SE, Brasil.

E-mail: zobolito@gmail.com; izidoro.renato@gmail.com

Recebido em: 28-05-2017 Aprovado em: 29-07-2017

DOI: http://dx.doi.org/10.22456/1982-8918.73698 (c) (1) (8) Licence 


\section{INTRODUÇÃO}

No contexto esportivo o corpo dos atletas comumente aparece associado a elementos de outras ordens: fenômenos "sobrenaturais" (magia, ilusionismo, paranormalidade, espiritismo); fenômenos naturais (físicos: raios, trovões, vento, furacões, terremotos; biológicos: animais); fenômenos humanos (política, tecnologia e arte).

O futebolista Andrés Iniesta (capitão da seleção espanhola na conquista do campeonato mundial de 2010), pelas suas habilidades com a bola, é conhecido como "O ilusionista". O maior velocista de todos os tempos, o jamaicano Usain Bolt (tricampeão e recordista olímpico dos 100, 200 e revezamento 4x100) tem o apelido de "raio", pela sua vertiginosa capacidade de ser veloz. O maior medalhista olímpico da história, o nadador norte-americano Michael Phelps, é chamado de "Tubarão" das piscinas, pela sua célebre capacidade de ser ágil na água. Pelé é nada mais e nada menos do que o "Rei" do futebol. A lenda tcheca do atletismo, Emil Zatopek, pelo seu ritmo frenético e compassado de correr, foi eternizada como sendo "A locomotiva humana". Copa do Mundo de Futebol do México, 1986, por uma vaga às semifinais jogam Argentina e Inglaterra, Maradona faz um gol antológico: "uma pintura".

Nos exemplos acima aparece um território de indiscernibilidade em que se misturam elementos de ordem humana e não humana, uma "multinatureza", para lembrar Viveiros de Castro (2002), na medida em que não mostram uma variabilidade de naturezas, mas as próprias variações como natureza e expressões desta (GIORGI, 2016). O que há é uma espécie de zona de indeterminação entre os fenômenos, na medida em que há uma relação entre elementos heterogêneos; elementos de ordens distintas que expressam uma multiplicidade de termos heterogêneos mas em comunicação.

Neste sentido, consideramos que cabe indagar: por que há essa necessidade de constantemente relacionar os corpos dos atletas a elementos de outras ordens: animais, manifestações de arte, máquina, fenômenos sobrenaturais, dentre outros? O que há no território esportivo que torna possíveis estas associações entre o corpo dos atletas e outros elementos de diversas ordens? O que a comunicação/relação entre estes termos heterogêneos no âmbito esportivo expressam?

É diante dessas indagações que o objetivo deste escrito é fazer uma leitura dessas associações/comparações entre os corpos dos atletas a essa multiplicidade de elementos heterogêneos a partir da filosofia de Deleuze e Guattari (2012) e sua leitura acerca de Spinoza (2013), mais precisamente utilizando-se dos conceitos de potência, devir e afectos. A partir desses conceitos consideramos que o fato de comparar ou dar nomes a atletas utilizando fenômenos de outras ordens expressa três pontos acerca da relação do corpo com 0 território esportivo: 1) essas comparações de atletas com estes fenômenos não são simples associações ou metáforas, mas devires; 2) esses devires expressam e tornam perceptíveis novas potências, ou potências estranhas dos corpos na relação com o esporte; 3) o território esportivo, paradoxalmente, além de ser um dispositivo disciplinar e de tecnificação do corpo, é também um território que possibilita a ampliação da potência dos corpos.

O presente ensaio está dividido em três partes: primeiro apresentamos os conceitos de potência, devir e afectos. Na sequência, buscamos ler as associações entre os corpos dos atletas com elementos de outras ordens a partir dos conceitos supracitados, na tentativa de compreender um pouco mais o que são essas associações, bem como o que elas fazem 
expressar do corpo e do território esportivo. Na terceira e última parte tecemos nossas considerações finais.

\section{DEVIR, POTÊNCIA E AFECTOS}

Para abordarmos os conceitos de devir, potência e afectos, faz-se necessário apresentar a concepção de corpo para Deleuze e Guattari (2012), segundo a leitura que ambos os filósofos realizam da filosofia de Spinoza (2013), haja vista que tais conceitos estão diretamente ligados ao corpo (pois dizem dos corpos), bem como a relevância e centralidade que o corpo tem para as obras e o pensamento destes autores.

Na filosofia de Spinoza (2013) a Substância ou a Natureza designa toda a realidade; efeito e causa de tudo que existe. Às qualidades desta Substância Spinoza nomeia atributos; 0 corpo faz parte do atributo chamado de extensão. O corpo é uma modificação da Substância; uma forma de manifestação/expressão desta. Para o filósofo holandês, a relação que temos para com o nosso corpo é de ignorância. Na proposição dois da terceira parte de seu livro Ética, o autor destaca que ninguém determinou até o momento o que o corpo pode ou não pode fazer. Por isso, a partir de Spinoza, Deleuze (2002a, p. 23-24) destaca que não sabemos o que pode o corpo: "[...] falamos da consciência e de seus decretos, da vontade e de seus efeitos [...] mas nós nem sequer sabemos de que é capaz um corpo [...] como dirá Nietzsche, espantamo-nos diante da consciência, mas 'o que surpreende é, acima de tudo, o corpo [...]".

Se tanto para Deleuze quanto para Spinoza a pergunta é "o que pode o corpo?", temos então que pensar uma concepção de corpo que busque investigar a potência deste. Assim, Deleuze (2002a, 2002b) destaca que, na Ética, Spinoza apresenta o corpo como um grau de potência que é expresso através de seu poder de afetar e ser afetado, e as afecções que fazem variar esse seu poder. Essa definição de corpo nos leva diretamente a pensar acerca dos conceitos de afecções, afectos e potência. As afecções dizem respeito ao estado do corpo afetado, implicando a presença do corpo afetante (DELEUZE, 2002a); são as inscrições ou marcas de um corpo no outro diante de um encontro entre eles. Já os afectos consistem na transição de um estado a outro (DELEUZE, 2002a). Dito de outra forma, é a variação ou passagem (aumento ou diminuição) de um grau menor a um maior (ou vice-versa) da potência dos corpos, e é justamente dessa potência que decorre a capacidade de agir do corpo: 0 afecto é a nossa própria potência em variação a partir das afecções que o corpo sofre.

Isso quer dizer que, a depender das afecções e dos afectos, a potência de agir do corpo é aumentada ou diminuída. Neste sentido, a potência corresponde à tendência a perseverar na existência, mantendo-se e se abrindo ao máximo à aptidão que o corpo tem para ser afetado (DELEUZE, 2002a). A potência do corpo equivale à sua capacidade de buscar estabelecer relações/encontros com outros corpos de modo que sua própria potência seja aumentada - afectos que ampliem a potência de agir do corpo. Por isso Spinoza (2013, p. 311), na proposição 38 da quarta parte da Ética, enfatiza que é útil ao homem tudo aquilo que possibilita ao corpo poder ser afetado de muitas maneiras, favorecendo o próprio corpo a perseverar em sua existência.

Assim, inspirados fundamentalmente em Spinoza, Deleuze e Guattari (2012) compreendem que um corpo não é definido por uma forma que o determine, nem como um sujeito que o determina, muito menos pelas funções que exerce. Para estes pensadores 
franceses, um corpo somente é definido por sua longitude e latitude. 0 primeiro conceito corresponde ao conjunto de elementos materiais que constituem o corpo a partir de relações de movimento e repouso destes elementos; o segundo diz respeito ao conjunto de afectos intensivos do corpo; os afectos de que ele é capaz sob seu grau de potência (sua capacidade de afetar e ser afetado).

O corpo e, por consequência, o ser humano, é longitude e latitude de tal modo que os elementos materiais (longitude), ao diferenciarem o modo de relação, diferenciam-se também os afectos experimentados (latitude) e vice-versa. Se um corpo varia seu modo de ser afetado, os encontros que ele produz, isso modifica tanto sua longitude quanto sua latitude. É importante destacarmos que os afectos, enquanto variação da potência, só são percebidos em um estado dado e vivido no corpo. Essa variação da potência só existe quando os materiais que constituem nosso corpo são afetados (quando sofremos afecções) por outros corpos.

É a partir daqui que adentramos ao conceito de devir. Se são os encontros entre os corpos que definem o seu conjunto de longitude e latitude, isso quer dizer que não é possível compreender os corpos sem estar em relação com outros corpos; que juntos formam um ambiente, um complexo ou sistema de corpos. O que está em jogo aqui são as composições de afectos; se os afectos de um corpo podem ou não comporem-se com os de outros corpos, modificando tanto seus elementos materiais quanto sua potência (DELEUZE; GUATTARI, 2012). O que interessa é mapear os afectos de um corpo num dado conjunto de encontros do qual ele faz parte.

Na medida em que os afectos nos fazem variar em longitude e latitude, segundo Deleuze e Guattari (2012), eles são devires. 0 devir, neste sentido, é uma passagem ou transição de uma potência do corpo a outra; uma modificação do corpo - sobretudo uma modificação intensiva. Ela se dá essencialmente em um território em que há encontros e misturas entre multiplicidades, independentemente da ordem dos elementos envolvidos nestes encontros, sendo que os corpos entram em devir quando estabelecem entre eles uma zona de vizinhança, uma afetação que os modifica, os fazendo "tornarem-se outros". Quando um corpo entra em devir com outro corpo, ele não está imitando esse outro corpo, pelo contrário, ele faz uso dos afectos produzidos nesse encontro tanto para se diferenciar de si mesmo, quanto do outro corpo, na medida em que coloca em variação as relações de suas partes extensivas, seus materiais (ou até mesmo colocando novas partes extensivas, novos materiais).

Por isso Deleuze e Guattari (2012) nos alertam que devir não é imitar. Quando se fala que um ser humano entra em um devir animal, não se trata de uma analogia, nem uma metáfora, mas de um modo de ser afetado que faça esse corpo entrar em variação: "É preciso que eu consiga dar às partes de meu corpo relações de velocidade e lentidão que o façam devir cachorro num agenciamento original que não procede por semelhança ou por analogia [...]" (DELEUZE; GUATTARI, 2012, p. 46).

É devido à constituição de um território afectivo que é composto por multiplicidades, elementos heterogêneos de diversas ordens; essas simbioses com "participações antinatureza" que Deleuze e Guattari (2010) destacam que os afectos são os devires não humanos do homem. Como destaca Giorgi (2016), o devir não é a descoberta das faculdades de um indivíduo, mas antes de tudo é o que passa entre os corpos, que expõem os corpos a outros rearranjos; que expressa a percepção e produção de outras potências dos corpos. Devir é "outrar-se", tornarse outro(s). É conquistar e tornar perceptível uma potência até então estranha e desconhecida ao corpo. 


\section{OS CORPOS DOS ATLETAS E OS DEVIRES}

A partir dos conceitos apresentados no tópico anterior, consideramos que o fato de comparar ou dar nomes a atletas utilizando-se de vários fenômenos de outras ordens expressa três pontos acerca da relação do corpo dos atletas com o território esportivo: 1) essas comparações de atletas com estes fenômenos não são simples associações ou metáforas, mas devires; 2) esses devires expressam e tornam perceptíveis novas potências, ou potências estranhas dos corpos na relação com o esporte; 3) o território esportivo, paradoxalmente, além de ser um dispositivo disciplinar e de tecnificação do corpo, é também um território que possibilita a ampliação da potência dos corpos.

No cenário esportivo é muito comum se fazer menção ao corpo e à performance dos atletas fazendo alusão a fenômenos de outras ordens a partir do ato de nomear, dar apelidos, fazer associações, comparar. Quando o futebolista brasileiro Júlio Baptista foi jogar no Sevilla ganhou da torcida o apelido de "La Bestia" (A besta/a fera), uma alusão à besta do apocalipse, que era uma fera, um monstro híbrido de animais como leopardo, urso, touro e leão - uma criatura de sete cabeças e dez chifres. $O$ ala armador norte-americano Kobe Bryant, que levou o Los Angeles Lakers a três campeonatos consecutivos da NBA (2000-2001-2002), é conhecido como "Black mamba" - Black mamba é uma espécie de cobra, a mais venenosa do continente africano.

O atacante Euller, ídolo de várias torcidas do futebol brasileiro pela sua velocidade, foi denominado "O filho do vento". O jogador de futebol argentino Alfredo Di Stefano - ídolo do Real Madri da década de 1950 - também ficou conhecido pela sua velocidade e levou o apelido de "La saeta rubia" (a flecha loira). O maior ídolo do basquete brasileiro, Oscar Schmidt, "fez chover" na final do basquete no pan-americano de Indianápolis em 1987 e ficou eternizado como o "mão santa". Durante a década de 1920, dono de 22 recordes mundiais e 12 medalhas olímpicas (nove de ouro e três de prata), o corredor de provas de fundo e meio fundo Paavo Nurmi era conhecido como o "Finlandês Voador".

Um dos maiores - senão o maior - boxeador de todos os tempos, o norte-americano Muhammad Ali definiu seu estilo de lutar da seguinte forma "flutuar como uma borboleta e picar como um zangão"; foi assim que o peso-pesado nocauteou 57 adversários em 62 lutas na carreira. "II trattore" (O trator) foi o apelido dado pelos torcedores da Inter de Milão ao lateral e volante argentino Javier Zanetti, pela sua raça e resistência - Zanetti foi campeão da Liga dos campeões em 2010 pela Inter. O piloto finlandês Kimmi Räikkönem, campeão mundial de Fórmula 1 pela Ferrari em 2007, por sua frieza ao pilotar ficou popularizado como sendo "O homem de gelo". Mário Kempes, um dos heróis da Copa de 1978 de futebol, conquistada pela seleção Argentina, ficou conhecido como "Il toro" (O touro). O jogador campeão olímpico 2016 de vôlei de praia Alison Cerutti responde pelo apelido de "Mamute" - por sua força e tamanho. O ponta-esquerda do Flamengo nas décadas de 1970-1980, Júlio César, foi comparado a "Uri Geller" e se eternizou com esse apelido pois "entortava" os adversários com seus dribles da mesma forma que o paranormal israelense (naturalizado britânico) entortava garfos e colheres. Melo (2005) destaca que podemos ver isso nos discursos que relacionam arte e esporte, ao ouvirmos expressões como: "a equipe joga por música"; "o time jogou como se coreografasse".

Todos esses apelidos ou heterônomos não são dados simplesmente porque eles se assemelham ou possuem características com tais fenômenos; não são simples metáforas ou 
meras associações, mas sim devires. Se dizemos então que acontece aí um devir "fenômeno", não significa dizer que há uma imitação destes elementos, ou a tentativa de se fazer destes. Os termos (Bestia, vento, trattore, black mamba...) não são necessariamente reais, o que é real é o devir; a passagem, a variação da potência expressa nos corpos desses atletas - o que é real são estas potências que se expressam entre os corpos dos atletas e os termos. Por isso Deleuze e Guattari (2010) nos esclarecem que o devir é real sem que sejam reais os termos que se devêm. Os autores destacam que devir não se identifica, nem corresponde, mas é um verbo que tem sua consistência em si mesmo, e que tais consistências são expressas nos corpos através das potências.

O que pode nos ajudar a compreender melhor tais fenômenos como devir é a consideração de que eles expressam uma potência até então desconhecida aos corpos, ou estranhas na relação entre o corpo do atleta e o território esportivo de afecções o qual o corpo produziu, até então, seus encontros. Peguemos, para isso, o exemplo do termo "Locomotiva humana" que é uma metáfora para representar Emil Zatopek em sua performance atlética. $E$ perguntamos: por que do ponto de vista spinoziano de Deleuze e Guattari "Locomotiva" não pode, ao menos, limitar-se a uma metáfora?

Segundo Japiassu e Marcondes (1996, p. 181), metáfora vem do grego methaphora e significa transposição. Sua função é "[...] representar uma qualidade definidora de outra". Grosso modo, apresentar à consciência de alguém uma coisa mediante a apresentação de outra coisa. A nosso ver, ocorre uma espécie de desterritorialização semântica de um termo; não se trata de uma transposição completa, mas de algumas qualidades correspondentes, no caso de Zatopek-Locomotiva, as qualidades rítmicas e de força. Para tanto, assumimos que essas denominações são metáforas; mas não é nelas que encontramos seus limites. A nosso ver existem comunicações que extrapolam as relações metafóricas - de tradução - entre corpos e nomes. As expressões lexicais e sintáticas não cumprem apenas a função de abstração; de fazer existir algo da imanência dos corpos no campo da expressão representativa; na medida em que essa busca alguma identidade - qualitativa ou quantitativa - entre uma coisa e outra; enquanto que as transposições aqui tratadas, em termos de devir, devem implicar a diferença ao invés da identidade; de modo que a substância não se confunde com seu atributo. $O$ atributo, resultado de um encontro entre corpos - substâncias -, afectos, portanto, produz no corpo do atleta algo que não é dele, não lhe pertence; que a ele não se assemelha, embora the seja adequado.

Por essa via, chamar Zatopek por um heterônomo, Locomotiva, não é uma forma de extrair uma semelhança entre um e outro, mas sim o elemento - 0 afectos - que produz a diferença naquele corpo, em relação - negativa ou positiva - às afecções anteriores. Não pode ser uma analogia, quem sabe seja uma "dialogia". Assim, o termo Locomotiva é que nos faz notar algo que possibilita o corpo de Zatopek se diferenciar de si mesmo; de saber que o ritmo que ele expressa se reduz a ele e vice-versa. Estamos no campo da expressão do devir, da potência que faz a diferença. Por isso, não é uma representação da coisa que está em pauta; mas a coisa mesma, que habita, combina ou compõe tanto um quanto outro no campo do corpóreo, extrapolando os limites da linguagem.

A problemática técnica ou eficiente que se engendra é pensarmos acerca de como 0 corpo de um atleta se torna adequado para ser habitado por um dado afecto e assim ganhar uma nova potência. $\mathrm{O}$ que na locomotiva se instala que lhe permite um dado ritmo e força? 
O que, em um corpo humano, instala-se para lhe permitir ser habitado por um dado ritmo e uma força que não Ihe pertence? Nas palavras de Spinoza (2009, p.162): "Não pode, pois, ocorrer que o homem não sofra quaisquer outras mudanças que não aquelas de que é causa adequada". Assim, como foi possível ao corpo de Zatopek uma devir-locomotiva? Como se tornou adequado para tanto? O primeiro entendimento de uma resposta possível é de que, no enunciado da referida proposição 4: "Não pode ocorrer que o homem não seja uma parte da natureza $[\ldots] "$.

Por conseguinte, considerando que faz parte da natureza, ou seja, do mesmo ambiente de objeto do qual participa a locomotiva, temos o primeiro quesito para então receber, Zatopek, um atributo - o mesmo atributo - recebido pela locomotiva por outros meios ou métodos. Spinoza (2009, p.205) continua a mencionar o mesmo tema no capítulo 7 do apêndice dessa mesma quarta parte. "Se [o homem] [...] vive entre indivíduos tais que combinam com a sua natureza, a sua potência de agir seráa [...] reforçada. Se [...] vive entre indivíduos tais que em nada combinam com a sua natureza, dificilmente poderán ajustar-se a eles sem uma grande mudança em si mesmo". Dadas as drásticas diferenças entre um homem e uma locomotiva, é certo que a locomoção e seus princípios mecânicos de alavanca tenham sido reforçados em Zatopek segundo sua potência de agir então estabelecida.

Contudo, para ele atingir não um reforço, mas uma ruptura com as afecções anteriores, produzir em si um devir, teve que provocar em seu corpo uma grande mudança para então poder compor ou combinar com o ritmo e a força da locomotiva, que não pertence naturalmente à locomotiva. Assim, o afectos produtor de devir no corpo de Zatopek é seu método intervalado - que trataremos a seguir. E a prova de que o método é a causa do atributo consiste em sabermos que quando um atleta deixa de se submeter a uma dada técnica, sua performance estética - expressiva - tende a regredir para as afecções anteriores; mas, sem perder de vista que algumas afecções do devir se mantêm impregnados em seu corpo, de modo que o retorno a ele é impossível e passado incontornável.

É verdade que, do ponto de vista anatômico ou fisiológico, por exemplo, o que o corpo de um atleta pode ou não pode fazer supõe características específicas e genéricas, que dependem de seus órgãos, membros e funções. Porém, do olhar da potência, "[...] as características orgânicas decorrem, diferentemente, da longitude e de suas relações, da latitude e de seus graus [...]" (DELEUZE; GUATTARI, 2012, p. 45). Do ponto de vista da potência, o que um corpo é capaz de fazer depende das relações às quais seus materiais extensivos são submetidos, bem como dos afectos que este corpo é capaz em uma relação.

Isso nos leva a investigar por que o território esportivo possibilita a produção destes devires. Nossa ideia é a de que o esporte pode ser considerado também um território que permite a ampliação da potência dos corpos dos atletas a partir da multiplicidade de elementos e relações que cada esporte possibilita aos corpos. Neste sentido, o território esportivo, fundamentalmente, pertence à ordem das afecções, isto é, em seu nível mais fundamental o esporte diz respeito a como os corpos são afetados e quais são os afectos produzidos e circulados a partir destas afecções.

Assim, o território esportivo demarcaria a latitude e a longitude dos corpos dos atletas; a capacidade destes entrarem em relações de composição com outros corpos (sejam estes humanos ou não), e seu grau de potência diante de uma determinada relação, de um determinado encontro. No território esportivo os corpos dos atletas são definidos por uma lista 
de afectos ativos ou passivos em função dos agenciamentos e encontros de que ele faz parte. O que interessa aqui é que as relações que o esporte oportuniza aos corpos são de uma dada multiplicidade que possibilita a estes entrar em devir, produzir outras potências e afectos.

O atleta norte-americano Dick Fosbury, na Olimpíada da Cidade do México, em 1968, surpreendeu o mundo ao vencer a prova do salto em altura no atletismo, além de estabelecer um novo recorde olímpico com a marca de 2'24 m, exibindo o potencial de sua nova técnica de salto. Fosbury tinha dificuldades em se adaptar aos dois estilos de saltos convencionais utilizados na época, o estilo tesoura e o estilo straddle - rolo ventral. Por ter tal dificuldade ele foi criando seu próprio modo de saltar. Foi assim que ele criou o salto que levou seu nome, "Salto estilo Fosbury", que consiste em fazer uma corrida de aproximação em linha curva até o sarrafo e então se impulsionar com a perna de fora e ultrapassar a altura de costas fazendo um arco. Tão logo sua técnica produziu um devir em seu corpo, toda a comunidade do salto em altura começou a se utilizar do estilo Fosbury para saltar.

Emil Zatopek ficou famoso não só pelos seus 18 recordes mundiais e pela façanha de ter sido o único atleta a ganhar numa mesma Olimpíada as provas de 5.000, 10.000 e maratona - Helsinque 1952. Ele entrou para a história do atletismo também por difundir o método de treinamento intervalado. Enquanto os outros atletas treinavam através dos famosos "longões" (treino de corrida com percursos de longas distâncias), Zatopek fazia repetições de tiros intercalados com descanso ativo ou passivo (100 x 200m; 40 x 400 m com intervalo de trote de 100 m). O método intervalado foi criado na década de 1930 pelo cardiologista alemão Reindell, que o utilizava com fins terapêuticos junto a seus pacientes. Porém, somente no fim da década de 1940 e início da de 1950 que Zatopek apresentou-o ao mundo através do atletismo. Este método de treinamento aumenta a capacidade de captação de oxigênio pelos músculos com menor produção de ácido lático, pois nos intervalos os músculos reabastecem as quotas de ATP-CP esgotados no período dos exercícios, compensando parte do débito de oxigênio e colocando novamente o ATP-CP como fonte geradora de energia (FOX; BOWERS; MERLE, 1992). Para a época Zatopek imprimia grande superioridade frente a seus adversários, pois seu corpo era treinado dentro de uma técnica que o potencializava para além do treinamento de seus oponentes.

Esta consideração acerca de que o território esportivo pode ampliar a potência do corpo nos leva a pensar sobre a sua condição paradoxal. Ao mesmo tempo em que o esporte é lugar privilegiado do tecnicismo, em que o treino representa uma tentativa de reificação e domínio do corpo, como nos lembra Vaz (1999), paradoxalmente são as condições dadas pelo esporte, isto é, as relações entre os múltiplos elementos que o esporte possibilita entrar em composição com os corpos dos atletas, que servem para estes corpos entrarem em devir, ou seja, conquistar novas potências.

Isso se dá na medida em que o esporte põe para o corpo do atleta a questão do limite de sua (im)potência: no território esportivo os corpos entram em movimento em função de um problema que surge diante das afecções resultantes do encontro entre os corpos e os diversos elementos que constituem o esporte, fazendo com que os corpos dos atletas busquem o aumento de sua potência. Visualizamos bem isso no exemplo de Fosbury, ao perceber sua impotência frente às condições e os modos de relações que os corpos dos outros atletas entravam no salto em altura, compreendeu que era preciso conceber outro modo de relação com os elementos da prova, operando assim um rearranjo tanto de seus materiais extensivos 
(longitude), assim como também da potência de seu corpo (latitude), produzindo uma nova técnica de salto, entrando em devir.

Essa ampliação da potência dos corpos não significa necessariamente um aumento na complexidade dos movimentos em um determinado esporte, por exemplo. Fundamentalmente significa pôr em variação a potência do corpo, isto é, fazer o corpo do atleta ser afetado de outras maneiras de modo a entrar em devir. O esporte, neste sentido, pode ser um território que produz encontros intensivos quando possibilita ao corpo do atleta a ampliação de sua aptidão de ser afetado. Foi isso que Zatopek e Fosbury fizeram ao darem aos seus corpos outras maneiras de entrarem em relação com os elementos que estavam/estão envolvidos no salto em altura e nas corridas de longa distância, por exemplo, produzindo assim novos modos de efetuarem suas potências.

Isso nos leva à tentativa de considerar a complexidade da relação entre o território esportivo e os corpos dos atletas. "Para além do bem e do mal", os devires que aqui buscamos mapear nos levam a considerar o território esportivo a partir da lógica da fita de Moebius haja vista a reversibilidade ou transmutação de impotências em potências (e vice-versa) dos corpos dos atletas que este território produz. Isto é, a condição de limite da (im)potência que pauta a relação destes corpos com o esporte nos revela uma espécie de avesso deles, na medida em que ir até este limite revelasse a potência inscrita nesta relação. Como nos lembra Lapoujade (2015), um sistema ou objeto nunca é fechado em si mesmo, há sempre relações com outros objetos que produzem linhas que os transbordam, que fazem surgir seu avesso. A relação entre os corpos dos atletas e o território esportivo tenciona justamente o limite que os faz transitar entre suas potências e impotências, ou seja, produz justamente devires.

\section{CONSIDERAÇÕES FINAIS}

Neste texto refletimos filosoficamente sobre a necessidade de os agentes do território esportivo constantemente apresentarem a prática discursiva de relacionar os corpos dos atletas a elementos de outras ordens: animal, arte, máquina, físico, sobrenatural, dentre outros. Para tanto, indagamos os possíveis fundamentos dessas associações nominais ou heteronominais entre 0 corpo do atleta e outros fenômenos. Investigamos as procedências das articulações anunciadas, segundo a apreciação que os filósofos Deleuze e Guattari realizaram da obra de Spinoza acerca de três conceitos spinozianos básicos: i) afectos; ii) devir; iii) potência. Foi com base nessa tríade conceitual que detemo-nos no problema da comunicação/relação entre uma extensa série de termos heterogêneos - heterônimos - no âmbito esportivo, em que os discursos sobre os corpos atléticos são comumente compostos, baseados em suas performances, mediante articulação com outros fenômenos.

$\mathrm{Na}$ abordagem da trilogia conceitual de Deleuze e Guattari - acima expressa compreendemos que se trata de uma releitura do trio conceitual spinoziano: a) afecções; b) afectos; c) potência, segundo o texto da Ética, de Spinoza. Podemos observar que o termo "devir" não está contido na mencionada obra de Spinoza. Ao menos nas traduções para a língua portuguesa o termo mais frequente é "mudança", enquanto que "devir" é uma produção contemporânea e pós-estruturalista da filosofia spinoziana. De qualquer modo, a dimensão conceitual de "mudança-devir" implica compreender que se trata de uma derivação do conceito de "afectos"; um efeito dos afectos aos quais um corpo pode ser submetido mediante encontro 
com outros corpos. Os corpos, assim, em contato, se transformam. E por essas transformações por relações os corpos podem se tornar mais ou menos potentes.

Como os corpos não nascem no nada, mas sim num mundo em que estão presentes outros corpos, tudo que - não - pode um corpo, expresso em seus comportamentos, é fruto das composições que forma com outros corpos presentes. Os demais corpos nos dão, portanto, mais ou menos poder. Que em termos de potência, de virtus, trata-se de um poder prévio virtual - a toda ação. Não obstante, ao passo que o encontro com um dado corpo é cessado, a potência do corpo antes afetado também pode ser subtraída; deixando de poder realizar certas ações então associadas aos encontros com o corpo agora ausente. Contudo, de todos afectos pode restar afecções, inscrições impregnadas no corpo afetado a partir do encontro; como se fossem memórias - registros - dos afectos que então o corpo carrega em sua história e, assim, mantém-se outro, diferente daquilo que era anteriormente ao encontro afectivo.

Esse outro corpo, diferente de seu passado no curso do tempo, que lhe possibilita potência - a ações futuras, que carrega em si as marcas dos afectos, as afecções, encontrará outros corpos que, possivelmente, Ihe proporcionarão afectos que, por sua vez, promoverão devir, mudanças, transformações, outras potências. Necessário frisar que cada encontro corpóreo implementa uma potência limite, em hipótese alguma infinita, na medida em que a pergunta "o que pode um corpo?", não pode perder de vista os limites de sua composição com o ambiente. De outro modo, a cada momento em que, por uma situação hipotética, os afectos se estabilizam por uma estagnação dos encontros, provocada por uma cultura técnica e tecnológica estruturada e estática, o devir também será congelado.

Nesses termos, conceber o devir ad infinitum dos corpos, segundo uma leitura spinoziana, consiste em contar com momentos de equilíbrio e desequilíbrio ambientais. Rupturas com os afectos presentes provocadas por outros afectos, desconhecidos. Mas, isso, sem perder de vista que, para cada ambiência afectiva existe um limite, uma dada potência. Assim, para transformar uma potência, é necessário que outros afectos entrem em jogo nas relações de alteridade. Para que as potências permaneçam no corpo, é necessário que os afectos deixem afecções na história desse corpo, que agora é outro.

Sobre isso, em seu Ética, terceira parte, intitulada "A origem e a natureza dos afetos", mais especificamente em seus "Postulados", Spinoza (2009) diz o seguinte: primeiro postulado: "O corpo humano pode ser afetado de muitas maneiras, pelas quais sua potência de agir é aumentada ou diminuída, enquanto outras tantas não tornam sua potência de agir nem maior nem menor". Segundo postulado: "O corpo humano pode sofrer muitas mudanças, sem deixar, entretanto, de preservar as impressões ou os traços dos objetos [...]". Lembrando que esses traços o filósofo também chama, subsequentemente no mesmo parágrafo, de "imagens".

Sob todos esses aspectos, o esporte é um território privilegiado para explorarmos a questão de Spinoza revisitada por Deleuze: "O que pode o corpo?". E pelo que vimos, os corpos dos atletas podem os devires do que eles são capazes! 


\section{REFERÊNCIAS}

DELEUZE, Gilles. Espinosa: filosofia prática. São Paulo: Escuta, 2002a.

DELEUZE, Gilles. Spinoza e o problema da expressão. São Paulo: Editora 34, 2002b.

DELEUZE, Gilles; GUATTARI, Félix. 0 que é a Filosofia? Trad. Bento Prado Jr. e Alberto Alonso Muñoz. São Paulo: Editora 34, 2010.

DELEUZE, Gilles; GUATTARI, Félix. Mil platôs: capitalismo e esquizofrenia. São Paulo: Editora 34, 2012. v. 4.

FOX, Edward L.; BOWERS, Richard; MERLE, L. Foss. Bases Fisiológicas da Educação Física e dos Desportos. 4. ed. Rio de Janeiro: Guanabara Koogan, 1992.

GIORGI, Gabriel. Formas comuns: animalidade, literatura, biopolítica. Tradução de Carlos Nougué. Rio de Janeiro: Rocco, 2016.

JAPIASSU, Hilton; MARCONDES, Danilo Metáfora. In: Dicionário básico de filosofia. 3. ed. Rio de Janeiro: Jorge Zahar, 1996. p. 129-130.

LAPOUJADE, David. Deleuze, os movimentos aberrantes. Trad. Laymert Garcia dos Santos. São Paulo: N-1 edições, 2015.

MELO, Victor de Andrade. A presença do esporte no cinema: de Étienne-Jules Marey a Leni Reifenstahl. Movimento, v. 11, n. 2, p.111-130, maio/ago. 2005.

SPINOZA, Baruch. Ética. Trad. Tomaz Tadeu. Belo Horizonte: Autêntica , 2013.

SPINOZA, Baruch. Ética. Trad. Tomaz Tadeu. Belo Horizonte: Autêntica , 2009.

VAZ, Alexandre Fernandez. Do culto a performance: esporte, corpo e rendimento. In: CONBRACE,10., 1999. Disponível em: <http://revista.cbce.org.br/index.php/RBCE/article/view/834/497>. Acesso em: 29 abr.2017.

VIVEIROS DE CASTRO, Eduardo. A Inconstância da Alma Selvagem e Outros Ensaios de Antropologia. São Paulo: Cosac \& Naify, 2002. 
Agradecimentos: ao Professor Hamilcar Dantas Junior pela lista de mais de 200 nomes de atletas com suas respectivas associações a fenômenos de outras ordens. 